\title{
A Crisis of Confidence in Higher Education: Is Technology the Solution?
}

Ray Archee*

Western Sydney University, Australia

\begin{tabular}{|c|c|}
\hline ARTICLE INFO & ABSTRACT \\
\hline $\begin{array}{l}\text { Keywords: } \\
\text { Higher Education } \\
\text { Technology } \\
\text { Blended Learning }\end{array}$ & $\begin{array}{l}\text { Higher education is one of the great successes of the twenty-first } \\
\text { century. Once the province of an elite few, a university degree is now } \\
\text { commonplace as the industrial revolution transforms into the digital age. } \\
\text { However, the process of teaching has not changed much since Aristotle } \\
\text { taught at the Lyceum: students still meet their teachers to listen and } \\
\text { ponder their words of wisdom. This process has become less desirable } \\
\text { for some students who now learn entirely online, or those who cannot } \\
\text { reconcile the cost of a degree with its overall employment benefits. } \\
\text { Dystopian theories have criticized current online educational practice as } \\
\text { leading to inadequate reading, poor recall and confused cognition. But } \\
\text { technology is seen by others as a panacea for rising costs, massive class } \\
\text { sizes and fully engaging digital native students. Universities and } \\
\text { colleges need to make some mindful decisions to curtail decreasing } \\
\text { interest, less funding and disruptive competition. Is technology a } \\
\text { saviour or an impediment in this process? }\end{array}$ \\
\hline
\end{tabular}

\section{Introduction}

For the last four years, at many Australian universities, domestic enrolments in some undergraduate degrees have been steadily falling. There is no obvious single explanation for this phenomenon - a university degree has been a predictably stable choice for students for over 25 years leading to a vast expansion of the industry sector in this country. Various explanations have been posited, from a nation-wide decline in tertiary degree choice, to competition from more attractive free courses, to poor information available on university websites. The reasons behind this decline in student numbers should be the subject of a research project, but given this has not occurred, commentators can only guess why this is occurring.

In Oct, 2019 the Australian government figures showed a 1.3\% decrease in total student applications to higher education degrees, and in 2018, applications fell by $2.6 \%$ (Australian Government, 2019). Unusually, the broad fields that showed the largest declines were Management and Commerce (9.1\%) and Engineering and Related Technologies (4.1\%), Agriculture, Environmental and Related Technologies (4.1\%), Creative Arts (3.0\%) and Education (1.2\%). The most popular fields were Health, and Society \& Culture (mainly the social sciences and literature). Most broad fields decreased by small margins.

Similar to many developed countries, Australian higher education has been increasingly affected by recruitment set-backs and constant government cost-cutting (Archee \& Gurney, 2007). Since 2005, most Australian institutions have employed some form of technological intervention, usually a learning management system, in order to solve simultaneous problems of curriculum development and student access. These systems extend the access of all programs of instruction, and in-house training but more importantly allay expensive infrastructure costs such as new staff, classrooms, libraries and facilities. At almost all Australian institutions, 
contact time with teaching staff has been reduced while instructors attempt to produce quality education with less face to face interaction. Australian students experience added pressure from higher fees, and increased living costs. Student part-time employment requires maximum flexibility in terms of attendance, curriculum support and off-campus access. Most aspects of higher education in Australia - delivery mode, research, administration, technical support, classroom facilities, curriculum design and assessment -have markedly changed over this period.

Early American research on public concern over higher education has been reported for decades but few successive governments have seriously considered the ramifications of a population that eschews a university degree. The history of a 'crisis in higher education' begins with Balderston \& Weathersby (1972) who identified questions of continuing relevance, doubts about continuing education and doctoral programs and the increasing financial burden of degrees for American families. A decade later, Eisenberg (1988) identified a number of issues at the time: the quality of higher education, opportunities for the populace, public understanding of the purposes of higher education, its relation to employment and economic development, and the cost of obtaining a degree. Fischer (2011) reported that in the post-GFC era, students have genuine apprehension over the full-fee cost of obtaining a degree versus the perceived benefit in the workplace. At that time, and in 2019, most students would not be attending ivy-league universities or prestigious research institutions, but would be enrolled at community colleges and private, for-profit institutions.

For the past five years, survey pollsters and educational media in the USA have been reporting significant ill-feelings about a university education (Marken, 2019) which have been displayed in declining enrolments in higher education across the nation. The overall domestic enrolments at mainly colleges has fallen for the seventh year in a row, currently down 1.7\% (NSC Research Center, 2019). The main deficits have occurred in liberal arts and humanities, which appear less drastic due to some gains in other areas. While these percentages may look small, the actual numbers are close to 300,000 students who have chosen not to enrol in a first degree. International students $(1,000,000+)$ more than make up for the loss of domestic students, but the reasons for the declines are yet to be fully comprehended, and certainly not yet fully felt in the industry.

The situation in the UK is comparable to the USA with domestic applications down $2 \%$ in 2018 , but explained by an equivalent lack of $18 \mathrm{yr}$ olds in the British population (The Guardian, 5 Apr, 2018). Nursing degree applications have declined $10 \%$ along with mature-age postgrads. Prior to 2019, nineteen institutions had reported operating deficits in 2016/17 creating sustainability questions amongst both staff and students (Times Higher Education, 2018). The lucrative international student market from the EU, which has kept the sector buoyant is now deciding whether to risk the Brexit no-deal, which could leave students financially disadvantaged in coming years because they would no longer enjoy EU discounted rates (ICEF Monitor, 2018). If one factors in changing student fee rates, increased tuition costs, and dubious government subsidies there is certainly a lack of confidence shared by potential new students, tertiary staff and administrators alike.

\section{Technology and higher education}

The use of technology in higher education closely follows the rise of personal computers in the 1980s and subsequent advancements in networking and software development, in particular the Internet and web browsers from about 1995. Before the Internet became ubiquitous throughout the world, computers, or 'microcomputers' to use the term at that time, were mainly used as substitutes for teaching in the form of instances of computer-assisted instruction and testing. These standalone applications were not restricted to higher education, with secondary and primary aged students also subject to this form of instruction. The use of such computer- 
assisted instruction was hailed as a saviour for repetitive tasks and rote learning. However, computer-based instruction has also been decried as being robotic, inhuman, and threatening jobs of skilled teachers and trainers (Billings, 1986; Hmelo, 1987). Many training courses in a range of professions, today have migrated to a simulated computer-assisted process but using web-based modules plus the usual competency test at the end. Anecdotal evidence from nurses, teachers and academics show a mixed set of attitudes towards these cost-saving modules.

The use of technology in higher education has been seen as one of the ways to simultaneously conserve spending, and also provide flexible access to students who wish to study online, ether fully or part-time (Marcom, 2014). But the question arises, does this technology really provide cost savings if the expense is falling student enrolments due to lack of interest and boredom? Is technology really a cost-effective way to generate capital, if in fact these systems create ongoing expenses, and more importantly, engender apathy on the part of students leading to increasingly high attrition rates for online course takers (Bawa, 2016)?

\section{The Faustian bargain}

It was Neil Postman (1998), who said that when we use new technology we are entering into a kind of Faustian bargain. Every new technology adds to our humanity by bequeathing novel benefits, but it also removes a part of our old identity, never to be replaced. For every advantage there is an equivalent disadvantage. This is true of almost all technologies one can think of, for example, the telephone wrecked telegraphy, the motor vehicle gave us traffic, and pollution, radio stopped us talking, video stopped us reading, the Internet has demoted the notion of expertise to the click of a Google button (Carr, 2010).

In Australia and other developed countries, technology in the form of websites and blended learning has been used to create savings for institutions because they can eradicate the costs of paper, filing cabinets, typists, printing and reprographics, stationery and photocopying, and paper-based assignments. The paperless office is not quite yet devoid of paper, but very few teaching staff receive paper in their pigeonholes, and students never use paper except for exams. These funds could be used to hire more staff, support more research and create better curricula. However, this cost saving seems to be more often used to pay for operational spending on computer hardware, software and increasing administration overheads. Higher education institutions have employed learning management systems (LMSs) for decades and used their own websites to both market the institution and provide information for staff and students ${ }^{1}$. Such systems are proclaimed as being equitable, open all hours, and accessible to anyone with an Internet connection. But as most students have discovered, navigating a university website is an exigent task, and submitting an assignment and obtaining feedback even more challenging.

The establishment and use of electronic submission of assignments would appear to simplify the whole process allowing students a freedom from anxiety from printing costs, traveling to locate campus assignment boxes and hoping that the assignment does not get lost. Electronic submission also assists instructors in obviating the transport of heavy loads of essays back and forth, and their storage for years, just in case a dispute might arise. But instead of the long queues of the analogue registration for tutorials, students often have to queue to submit their digital assignments at heavy use times via the LMS. The same students may receive a receipt for their submission only to find that the assignment is invisible to mark on the grade centre interface. The problems continue when the assignments are returned and students cannot locate the right button to view their feedback. Anxiety over assignments has not been removed, it has just been displaced.

\footnotetext{
1 This situation is not the same in poorer, developing countries which are aspiring to copy the West.
} 


\section{MOOC qualifications}

There is a movement in higher education for more and more teaching resources to be placed online. This is true of traditional universities/colleges and especially the open access institutions that have begun to offer certificates of completion. In 2012, two large American universities Harvard and MIT partnered to form the conglomerate, edX. A year later ten Chinese universities together formed a copycat, XuetangX. Other universities such as Stanford, Princeton, Duke, and overseas, Tsinghua, Peking and Edinburgh universities also offer open education that does not select students on merit. Anyone can sign up either freely, or for a small cost, and study a range of courses taught by some of the best instructors in the world. Citizens of all countries may participate in these programs of study seemingly allowing low socioeconomic students, and those from developing countries access to higher education for a very low cost. The value of these certificates is allegedly gaining equivalence with traditional degrees, but employer confidence is a hurdle that needs to be overcome, given the possibility of cheating and collaboration with these new programs.

The official title of these open access programs is MOOC or Massive Open Online Courses and by the end of 2012 the US platforms had about 2 million registrants, but average completion rates were varyingly said to be around 15\% (Jordan, 2015) or about 3-5\% (Coffrin, et al, 2014). Such low completion rates do not seem to be a real competition for traditional higher education providers and as such cannot be said to represent a real threat to the benefits of obtaining a structured traditional degree. The MOOC community themselves have compiled a list of possible problems that are equally applicable to online programs in general: 1. Digital fluency is necessary, not just literacy; 2. Costs in terms of effort for participants may be too high; 3. Participants need to set their own goals and regulate their own learning; 4. Most programs are in English creating possible language barriers; 5. Programs feel chaotic because participants create their own content (Ingede, 2011).

MOOCs have been affirmed as one of the futures of higher education (Ubachs, Konings \& Nijsten, 2019). They can be democratizing, highly cost-effective, inclusive of all cultures and extremely attractive. If these online courses do become the accepted norm, then higher education will certainly be radically transformed. However, given the political and economic backlash from the entire higher education sector, worldwide, including students themselves, MOOCs cannot be seen as a serious threat to higher degree enrolments, in 2019.

\section{Learning and teaching are different within heterogeneous disciplines}

One of the major problems with using technology to solve enrolment issues, improve engagement and perhaps counteract student attrition is that the crisis of confidence is a multidimensional problem requiring more than one solution. Not all academic disciplines are affected by the reduced numbers, and not all disciplines agree on the same underlying aims, teaching methods or cultural capital (Lucietto, Russell \& Schott, 2018). The humanities are quite distinct from the sciences, and both are in turn very different to business and health disciplines. Given the vast differences between the various disciplines that comprise a modern university, how can any technology persuade an already sceptical and wary audience to enrol? While the Internet has certainly permitted the establishment of online, blended, and distance modes of information delivery in the form of learning management systems, the actual information catalogued on websites is immensely different for each disciplinary area. Student interaction with this disciplinary knowledge is also highly related to the objectives of the disciplines themselves, that are fine-tuned at the individual unit level.

Martin (2007) discusses a common factor that unites all the disciplines and this is the use of writing as the predominant form of assessment and outcome for learning. Writing both symbolizes and exhibits the central foci of that discipline. He gives the example of the lab experiment as way of understanding these differences. The lab experiment is designed to allow 
chemistry students access to fundamental scientific processes and how to apply empirical methods to the physical world. Students all enact the same process with the same equipment and this behaviour gives them basic experience. But the experiment is just the first step because it is the writing of the lab report that frames the scientific method that needs to be followed. Thus, the lab report becomes the main outcome of procedural and theoretical knowledge of the discipline. Reports exist in the humanities as well, and are often called essays, but their underlying procedures and theories are not the same.

Martin hypothesises 4 meta-genres of assessment that could assist administrators in conceptualising the modern university and their student engagement and retention: 1 . Problemsolving related to the professional area, 2. Empirical enquiry (using the scientific method), 3 . Library enquiry, 4. Performance and object creation (as in Art). If we accept these meta-genres and append the knowledge bank approach to distinguishing disciplines, then it is clear that specific technologies may assist students, but these technologies are not broad-ranging, nor immediate innovations accessible through current learning management systems, or blended learning pedagogies. The software needs to be written for specific purposes of disciplines or schools. In many cases bespoke software may be very beneficial to particular disciplines or courses, but this customization usually comes at significant cost, and is not a typical resource of the budget of already financially stretched schools or institutions.

\section{New students need audience analysis}

The key to evaluating MOOCs, blended learning, digital degrees and traditional classrooms is the student, not the technology to be used, or even the instructors who may spend countless hours designing curricula. Obviously if course quality and access are givens then programs need to be well designed, and students need to have access to computers and Internet services, but it is the individual characteristics of the audience that will make the program of study, a success or a failure. The students' attitudes towards not only technology, but learning itself should be an issue in the educational research literature directed at evaluating platforms and pedagogies of educational technology. Students should be the centre of attention, however they are more often viewed as a blank slates to be acted upon by an instructor, a technology, or a program of study. What is missing is understanding the expectations, student needs and existing attitudes at the very beginning of entering the institution. In short, who are the recipients of the teaching program, and how do they interact with the materials available in the learning environment?

A fairly recent paper by Henderson, Selwyn, Finger \& Aston (2015) reviewed a broad crosssection of students' everyday engagement with technology in two Australian universities and found some surprising results. While students all own a laptop or desktop computer their usage of this device is mostly constrained to looking up various websites and using social media. Increasingly smartphones were also being used as part of their daily use of educational devices. However, perusing university websites for information and resources is not a daily occurrence at home or at uni. The study showed that only 59\% of students categorised the actual LMS content and resources as being very useful to their learning. Using the library's online resources was rated higher at $66 \%$ very useful. These figures are somewhat bizarre in that digital services for doing assignments were more positively regarded than the actual websites that presumably constituted their entire learning content for the degree. Finding references for an assignment was a better use of a student's time and energy than learning about the actual course content. This seems to be an indictment of the LMS content or the students' overall interest and motivation, or both.

The author's figures from 5 years' worth of Blackboard analytics for taught units confirm that using the LMS is usually only performed once a week per unit, on average by the majority of students, and this occurs mainly in class (Archee, 2015). The inference is that students use 
technology in a peripheral fashion, and while the curriculum expectation is $8 \mathrm{hrs}$ of reading/study, that figure is grossly over-estimated from the actual times retrieved. If students only visit the weekly webpage once a week, and only for about 30 mins on average, then they do not read all the weekly material on the webpage. The same is true of weekly references, resources and custom videos that now replace face to face lectures. Observation of student behaviour in the class computer labs show individuals browsing and clicking. Writing is rarely contributed in terms of note-taking, unless students are asked to engage in a reflective or participative activity assigned for that particular class session. Online students have similar behaviour patterns.

Another more recent survey of Australian communication students at a large metropolitan university showed some ambivalence with their hybridized blended learning degrees (Archee, 2019). The Bachelor of Communication degree's units could be studied in face to face mode or online mode or any combination. Students could mix and match modes of delivery each semester. Few students were extremely happy with their degree with satisfaction scores being positive but lukewarm. The most telling part of the survey was that of the sample of 129 students, the vast majority of $84 \%$ did not prefer to study in the wholly online mode that was available to them. Most students had taken either one or zero online units. The attitudinal survey scores were all negatively skewed and thus median scores were the best choice of statistic. Highlights were median scores of 4 (out of 7) for 'Preferring more paper-based resources', 'Blackboard helps me improve my writing', and 'Prefer more online classes' showing polarisation of opinion here or perhaps no opinion whatsoever.

The survey revealed marked experiential differences between two clear groups: those students who had taken more than one online unit, and those who did not enjoy this mode of delivery. These experiential disparities were significantly different $(\mathrm{t}=2.78, \mathrm{df}=79, \mathrm{p}<0.01)$ on the Likert item 'I would enjoy my education more if more class time was FTF'. The highly experienced, online group disagreed significantly more than the classroom students. Doing a single online unit made little difference to opinions of classroom preference students. The difference of enthusiasm for the classroom vs online seems to be a function of undertaking quite a few, presumably successful, online units. This indicates that the online mode is highly suitable for a fairly small percentage of students, probably less than $10 \%$ of the cohort. But the fact remains that the majority of the students did not appear to appreciate the wholly online delivery mode, and thus chose not to take-up online units, unless completely necessary.

Not much has changed since Nordstrom (1988) reviewed computer-assisted instruction and concluded that the novelty of CAI assists low-level students to use the computer program, but higher-level students are unconvinced of the merits of the computer and rapidly become complacent and bored. This is exactly the experience of most students when they use a LMS in 2019. Why do we believe that placing information and resources on a website will be engaging for students and keep them studying at their particular institution? Cost savings might be accruing, but the students themselves are not viewing the custom-made weekly videos, nor reading the focused content and references on those web pages.

\section{Is Google really making us stupid?}

This question was posed by Nicholas Carr (2008) and has particular relevance to using technology to solve the crisis of confidence because it asks if the recreational use of online materials negatively impacts human learning and reading behaviour, especially in terms of students. Carr, and others have implanted a decade of debate that university administrators seem to be totally ignorant about, or prefer not to engage with. The tongue-in-cheek question is not about Google or even the Internet, but relates to the fact that most students in 2020 do not read articles from start to finish - they appear to suffer a kind of attention deficit disorder. They scan headlines, peruse photographs, and become easily distracted because of online 
reading habits originating from earlier experience with television, computers and their daily use of smartphones. When tested, such students do not remember what they have read, and certainly do not fully understand the entire content of online material. It is as if all online content is available for download, and thus not worth memorizing because the answer is a web click away, 24/7. That is, online content is purely functional knowledge and not worth learning because it is so easily retrievable.

The problem with this somewhat regressive approach to information retrieval and learning is fully explained by using an example of a native speaker of German and a non-native speaker who uses a German dictionary app. The dictionary user can interact in German in very basic, but quite functional ways, whereas the native speaker has genuinely learnt the language since birth. The dictionary user might be said to be somewhat functional in German, but the native speaker is totally fluent, they not only speak the language, but they think in German and can manipulate the language in complex and highly sophisticated ways. This example highlights the superficial way that many students treat their educational materials as mere information to be skimmed, but not digested completely. Such students may be able to navigate the issues and concepts of any given topic, but do not have the necessary understanding to be able to problem solve or generalise - in short, they have superficial understanding of their course content, because they have only viewed sub-headings and a few sentences of online paragraphs. This may explain why many students, when asked, prefer to attend class - they do not need to read anything because their instructors' explanations and clarifications substitute for their own minimal engagement with complex content.

An early experiment that empirically tested Carr's premises and warnings was a study by Hooper \& Herath (2014) who surveyed 202 students about their reading behaviour. Their sample was international with range of ages up to 50+. Results showed that online reading was certainly advantageous, but the majority of the respondents preferred paper-based reading. Reading from a screen was used for work-related tasks, with paper mainly reserved for recreation. Time of day was an important predictor with reading from paper (books) occurring late in the evening, before bedtime. Results showed participants reported much higher levels of comprehension, concentration, content absorption, recall, and relaxation while reading paper materials when compared to reading online.

Several other studies have found classroom tuition to be superior to purely online instruction in a range of areas: exam performance (Glass \& Sinha, 2018); interaction (Joshi, 2017); and economics instruction (Bennet, McCarty \& Carter, 2011). An opposing set of studies have found that classroom and online locations produce similar outcomes, and are thus seemingly equitable (see Humphrey, 2016). Few studies proclaim the outcome advantages of online learning over the classroom.

\section{Technology and disability}

A web-based higher educational culture, which has become the norm in all developed nations, unquestionably disadvantages students with certain kinds of disabilities such as blindness, partial sightedness and cognitive impairment, at the same time as assisting mobility-impaired students who cannot easily attend classes. An institutional decision to use LMSs and abstain from old fashioned paper is a trade-off between flexibility and disability. The creation of Braille versions of teaching materials is not a regular occurrence at most institutions, nor should it be because student activities comprise much more than student-centred web searches and library research. While screen readers are available for these searches, there are no easy solutions to the use of Excel for chart preparation, Photoshop for editing graphics, Powerpoint for oral presentations, SPSS for statistical research, and so on. Disabled students have difficulty collecting information, presenting that information, and preparing assignments for submission - essential activities that even non-disabled students struggle to master. 
In terms of websites, many higher education institutions supply the bare basics of Alt-tag text labels for graphics, semantic headings for extended documents, and functional colour schemes. However, most institutions also devolve accessibility responsibility to the LMS vendors and assume that their accessibility credentials are valid, making the websites usable. This assumption is simply false. LMS vendors proudly state that their systems are $\mathrm{W} 3 \mathrm{C}$ compliant, but they do not show how they have arrived at this surety. This author consulted a profoundly blind advisor, who used the JAWS assistive screen reader at the Australian Royal Blind Society in 2001 and discovered that WebCT, the forerunner to Blackboard, was inaccessible because of inadequate navigation assistance and many dead links. A decade later, Conway (2010) tested Blackboard with the JAWS program and by using a range of automated and manual methods and found that the LMS scored "better than average", but that score did not produce accessible content. Missing sitemaps, incapacity to locate user website location, variable page layouts, absent META data elements, use of unreadable pdf files, and missing ALT text labels for graphics were commonplace. Other brands of LMS do not fare much better when those systems are properly tested and assessed.

The overlooked aspect of blended learning is that it extends well beyond LMS information retrieval. Blended learning also comprises the student face-to-face and online interaction with instructors and peers, the writing of assignments, submitting assignments to online evaluation sites, sitting exams, tests and quizzes, and receiving feedback. Every one of these activities is a possible source of accessibility problems, rarely considered in the literature, and given scant recognition in the $\mathrm{W} 3 \mathrm{C}$ guidelines.

A challenging task is the frequent requirement that a student electronically sign a pdf copy of the institutional cover sheet to accompany all electronically submitted assignments. This obligation from the past is still mandatory at many institutions. The disabled student needs to download the cover sheet pdf, to open it in Acrobat, then insert a file of their signature, save the file, convert it to a Word document, and then add the cover to the beginning of the essay, then upload to the LMS. This is a tricky process for able-bodied students, but is very stressful and prone to errors for disabled students. The student must own a full version of Acrobat, MS Word and Photoshop in order to accomplish a legacy task from when students simply signed the front cover of their assignments. A simple solution would be to offer disabled students the alternative of submitting hard copy.

\section{Conclusions}

This paper began by asking if technology can solve the pressing problem of the crisis of confidence in higher education. It then asks whether technology is itself a solution or a problem. Neil Postman's adage, that technology giveth and taketh away is still a useful perspective. After 25 years, we are at the tail end of the blended learning and online education 'gift' and need to evaluate the 'loss' part of the equation.

First, we need to understand how students implement the technology that they find useful, and not assume that administrators or instructors automatically understand their needs or motivations. This means researching the needs of students from the ground up, not merely surveying how they use the technology that we want them to use. Higher education students are clearly not making creative or massive use of their institutional digital services during their degree. Students are unimpressed with video lectures, whatever the topic, and whomever the speaker. While a few students may be digital prodigies, the majority of students are fairly ordinary computer 'geeks' - they are computer literate, but not computer fluent.

We need to identify what has been lost in employing current all-encompassing digital displays of information, digital assignments, and electronic feedback. If you ask students what they read, many will usually reply books and magazines in traditional paper format. Why have we 
decided to delete paper and textbooks from our institutions, as if paper was somehow an inferior product? Disabled students appreciate paper, in fact, paper handouts are always appreciated in my 30 years of experience. We have downgraded our publishing industries, our newspapers and magazine culture, and our higher education to a single, albeit multi-faceted, computer or mobile phone screen. Most classroom students, if asked, do not really want to study their degree completely online, without coming to class. They say that it is far too hard, and too isolating to study from a computer screen. Society has changed because of the belief that digital is the future.

It is imaginable in the near future that a prestigious university will make its name by claiming to be $100 \%$ analogue in terms of its curriculum offerings. It may also garner exceptional staff who understand the limits of blended learning. It may attract students who are more appreciative of charismatic face-to-face teachers, interactive discussion, and feedback that contains personalized handwriting to explain errors and mistakes.

Higher education needs to ask itself what its role should be in the somewhat banal reality of the present, and not assume that they should predict the future of education. The current popular debates surrounding pedagogy and technology need to be subordinated to a recurring concern for the basic, analogue dimensions of the teaching academy: curriculum content relevance, recognition of distinctly different disciplinary pedagogies, assurance of appropriate teaching methods, meeting student educational expectations, and satisfying assumptions surrounding engagement and genuine learning. If these questions can be answered then solving the crisis of confidence may just be possible. The belief that technology alone will solve this problem is simply folly.

\section{References}

Archee, R. (2019). Evaluating a blended/online degree, Proceedings of the $8^{\text {th }}$ Teaching and Education Conference, 17-20 Sep, Vienna, Austria. Electronic document from https://www.iises.net/proceedings/8th-teaching-education-conference/table-ofcontent/detail?article=evaluating-a-blended-online-degree. Retrieved 20 Jan, 2020.

Archee, R. (2015). Is blended learning making us stupid, too? Open Journal of Social Sciences, 3(9), $65-70$.

Archee, R. and Gurney, M. (2007). Cultural accessibility in e-learning management systems: Cultural artefacts of WebCT course design, IADIS International Conference on E-learning, Lisbon, Portugal, 6-8 July, 2007.

Australian Government, Department of Education (2019). Undergraduate applications, offers and acceptances, 2019. Electronic document https://docs.education.gov.au/system/files/doc/other/dept_of_education__undergraduate_applicationsoffers_and_acceptances_2019.pdf. Retrieved 20 Jan, 2020.

Balderston, F. E., \& Weathersby, G. B. (1972). PPBS in higher education planning and management: From PPBS to policy analysis. Research Program in University Administration at the University of California, Berkeley, vol. Paper P-31. Berkeley, California: Ford Foundation.

Bawa, P. (2016). Retention in online courses: Exploring issues and solutions-a literature review. SAGE Open. https://doi.org/10.1177/2158244015621777

Bennett, D. McCarty, C., \& Carter, S. (2011). Teaching Graduate Economics: Online vs. Traditional Classroom Instruction. Journal for Economic Educators 11(2): 1-11. Electronic document from: http://capone.mtsu.edu/jee/2011/fall/1_MS411_pp1to11.pdf. Retrieved 22 Jan, 2020.

Billings Diane M. (1986). Advantages and disadvantages of computer assisted instruction. Dimensions of Critical Care Nursing, November-December 1986 
Carr, N. (2008). Is Google making us stupid? What the Internet is doing to our brains. The Atlantic, Jul/Aug, 2008. Electronic document from https://www.theatlantic.com/magazine/archive/2008/07/is-google-making-usstupid/306868/. Retrieved 20 Jan, 2020.

Carr, N. (2010). The shallows: What the internet is doing to our brains. WW Norton \& Co: New York.

Carter, M. (2007). Ways of knowing, doing, and writing in the disciplines. College Composition and Communication, 58(3), 385-418. Retrieved Jan 23, 2020, from www.jstor.org/stable/20456952

Coffrin, C., Corrin, L., de Barba, P., \& Kennedy, G. (2014). Visualizing patterns of student engagement and performance in MOOCs. Proceedings of the Fourth International Conference on Learning Analytics and Knowledge. LAK '14. New York, NY, USA: ACM. pp. 83-92. doi:10.1145/2567574.2567586.

Conway, V. (2010). Web accessibility issues with Blackboard at Edith Cowan University. eCULTURE, $3(1), 12-19$. Electronic document, retrieved from http://ro.ecu.edu.au/eculture/vol3/iss $1 / 2$ on 29 June, 2019.

Eisenberg, R. (1988). Higher education's crisis of confidence. AGB Reports, 30(6), 29-31.

Fischer, K. (2011). Crisis of confidence threatens colleges. The Chronicle of Higher Education, May 15, 2011.

Glass, A.L. \& Sinha, N. (2018): Classroom instruction results in better exam performance than online instruction in a hybrid course. The Journal of General Psychology, DOI: 10.1080/00221309.2018.1494128

The Guardian (2018). University applications fall despite surge in foreign students. Electronic document from https://www.theguardian.com/education/2018/apr/05/university-applications-falldespite-surge-in-foreign-students. Retrieved, 14 Oct, 2019.

Henderson, M., Selwyn, N., Finger, N. \& Aston, R. (2015). Students' everyday engagement with digital technology in university: exploring patterns of use and 'usefulness'. Journal of Higher Education Policy and Management, 37(3), 308-319. DOI: http://dx.doi.org/10.1080/1360080X.2015.1034424

Hmelo, C. E. (1989). Computer-assisted instruction in health professions education: A review of the published literature. Journal of Educational Technology Systems, 18(2), 83-101. https://doi.org/10.2190/93ND-6Y9D-023U-0RJD

Humphrey, J. Y. (2016), "A Quantitative Assessment and Comparison of Conceptual Learning in Online and Classroom-Instructed Anatomy and Physiology". Dissertations - ALL. 436. htps://surface.syr.edu/etd/436

ICEF Monitor (2018). UK higher education under pressure. Electronic document from https://monitor.icef.com/2018/12/uk-higher-education-under-pressure/

Jaffe, W. F. (1989). A Comparison of the Effects of Computer-Assisted Instruction With Printed Instruction On Student Learning in a Hospitality Management Course. Hospitality Education and Research Journal, 13(3), 53-59. https://doi.org/10.1177/109634808901300305

Jordan, K. (2015). MOOC completion rates. Electronic document from www.katyjordan.com. Retrieved, 14 Oct, 2019.

Joshi, C.A. (2017). Comparative analysis on effectiveness of classroom teaching and web-based teaching: teaching quantitative methods \& techniques. Working Paper No. 204/2016-17 Postgraduate Studies and Research Department, College of Banking and Financial Studies. Electronic document from http://www.cbfs.edu.om/UploadsAll/204-2016-17.pdf. Retrieved 22 Jan, 2020.

Ingede (2011). Explore a new learning frontier: MOOCs. Electronic article from https://learningsolutionsmag.com/articles/721/explore-a-new-learning-frontier-moocs 
Marcum, D. (2014). Technology to the rescue. New York NY, Ithaka S+R.

Lucietto, A., Russell, L. \& Schott, E. (2018). STEM educators, how diverse disciplines teach. Journal of STEM Education, 19(3), 40-46.

Markem, S. (2019). A crisis of confidence in higher ed. Blog article located at: https://news.gallup.com/opinion/gallup/248492/crisis-confidence-higher.aspx

National Student Research Clearinghouse Center (2019). Current Term Enrolment Estimates, Spring, 2019. Electronic document from https://nscresearchcenter.org/wpcontent/uploads/CurrentTermEnrollmentReport-Spring-2019.pdf. Retrieved, 14 Oct, 2019.

Nordstrom, B. H. (1988). Computer-assisted instruction: A review of research on the effectiveness of CAI. Arizona: Geographic Source. (ERIC Document Reproduction Service No. ED301 409).

NSC Research Center (2019). Current Term Enrolment, 2019. Electronic document from https://nscresearchcenter.org/currenttermenrollmentestimate-spring2019/. Retrieved 15 Nov, 2019.

Postman, N. (1998). Five things we need to know about technological change. Speech delivered in Denver, Colorado, 29 Mar, 1998.

Shapiro, D., Dundar, A., Huie, F., Wakhungu, P., Bhimdiwala, A., \& Wilson, S. E. (2019, February). Completing College: Eight Year Completion Outcomes for the Fall 2010 Cohort (Signature Report No. 12c). Herndon, VA: National Student Clearinghouse Research Center

Times Higher Education (2018). Growing English deficits trigger sustainability fears. Electronic document from https://www.timeshighereducation.com/news/growing-english-deficits-triggersustainability-fears. Retrieved, 15 Oct, 2019.

Ubachs, G., Konings, L. Nijsten, B. (eds) (2019). The 2019 OpenupEd trend report on MOOCs. Electronic document from https://openuped.eu/images/Publications/The_2019_OpenupEd_Trend_Report_on_MOOCs.pdf Retrieved 12 Nov, 2019. 